This item was submitted to Loughborough's Research Repository by the author.

Items in Figshare are protected by copyright, with all rights reserved, unless otherwise indicated.

\title{
Deterministic and reliability-based design: veneer cover soil stability
}

PLEASE CITE THE PUBLISHED VERSION

http://dx.doi.org/10.1680/gein.2008.15.1.1

\section{PUBLISHER}

() Thomas Telford Publishing @ ICE Publishing Ltd.

\section{VERSION}

AM (Accepted Manuscript)

\section{LICENCE}

CC BY-NC-ND 4.0

\section{REPOSITORY RECORD}

Sia, Hung-Ing, and Neil Dixon. 2019. "Deterministic and Reliability-based Design: Veneer Cover Soil Stability". figshare. https://hdl.handle.net/2134/10293. 
This item was submitted to Loughborough's Institutional Repository (https://dspace.lboro.ac.uk/) by the author and is made available under the following Creative Commons Licence conditions.

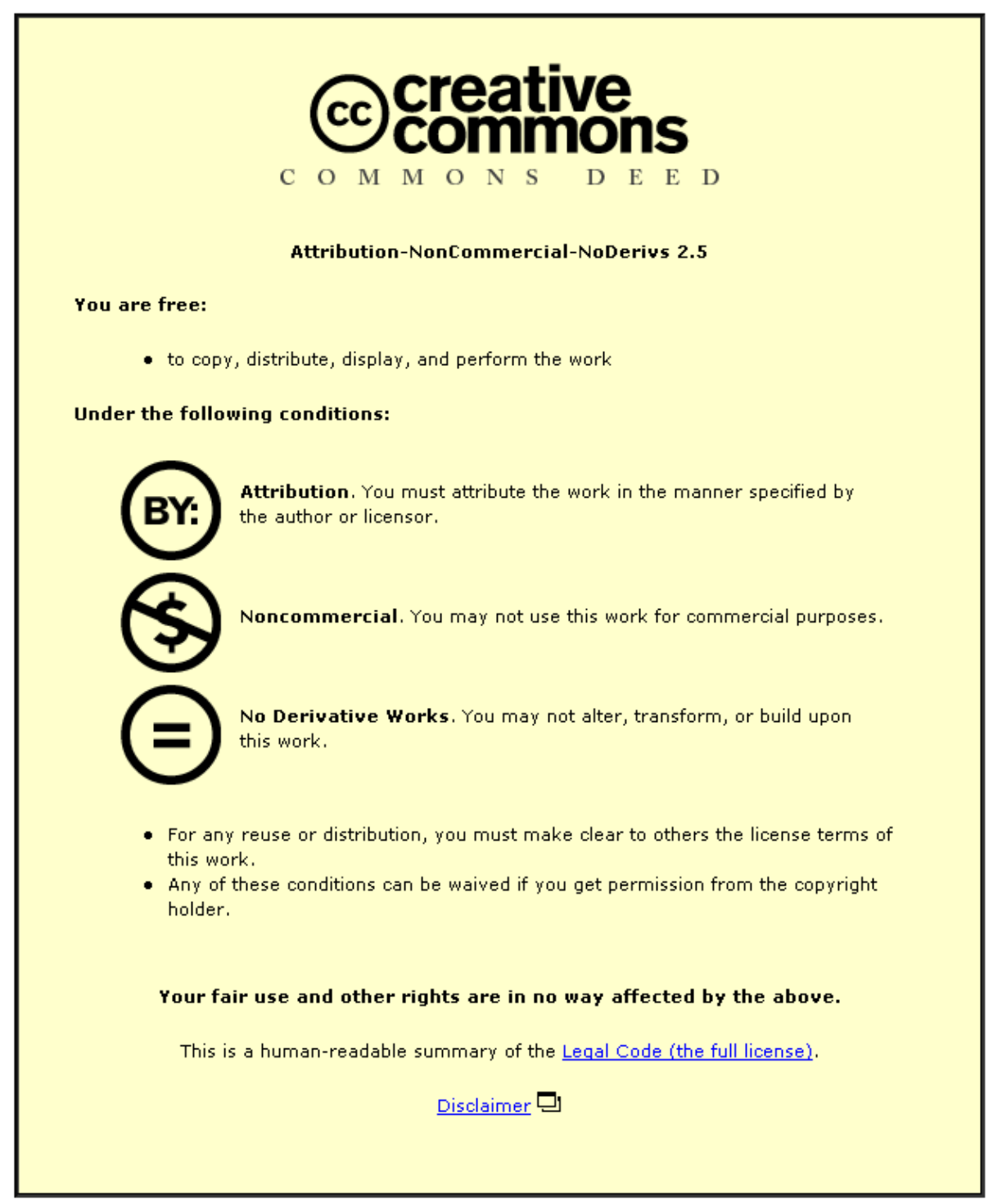

For the full text of this licence, please go to: http://creativecommons.org/licenses/by-nc-nd/2.5/ 


\title{
Deterministic and reliability-based design: veneer cover soil stability
}

\author{
A. H. I. Sia ${ }^{1}$ and N. Dixon ${ }^{2}$ \\ ${ }^{1}$ Research Student, Department of Civil and Building Engineering, Loughborough University, \\ Loughborough, Leicestershire, LE11 3TU, UK, Telephone: +44 (0)1509 223780, Telefax: +44 (0)1509 \\ 223945,E-mail:a.sia@lboro.ac.uk \\ ${ }^{2}$ Professor, Department of Civil and Building Engineering, Loughborough University, Loughborough, \\ Leicestershire, LE11 3TU, UK, Telephone: 01509 228542, Telefax:+44 (0)1509 223945, \\ Email:n.dixon@lboro.ac.uk
}

Received 16 March 2007, revised 24 September 2007, accepted 24 September 2007

\begin{abstract}
A design chart is a graphical tool that provides solutions to different scenarios of a system. In this paper, two types of design chart are developed based on deterministic and reliability-based analyses for determining the interface shear strength required for stability of a cover system to achieve a target safety factor of 1.5 and failure probability of $1 \times 10^{-2}$. The deterministic design chart assists in the selection of different types of geosynthetic for lining materials based on the required interface shear strength for stability, and the reliability-based design chart enhances decision-making by taking into account the uncertainties in the design parameters, such as the variability of interface shear strength parameters. Additionally, the latter chart can also be used to determine the optimum slope angle for a containment facility that will satisfy both the target factor of safety and acceptable failure probability. Examples are provided to illustrate the use of the design charts in estimating the minimum required interface shear strength and their allowable variability for a given veneer cover, and the optimum slope inclination corresponding to different interface shear strengths and their associated variability.
\end{abstract}

KEYWORDS: Geosynthetics, Reliability-based design, Veneer cover system

REFERENCE: Sia, A. H. I. \& Dixon, N. (2008). Deterministic and reliability-based design: veneer cover soil stability. Geosynthetics International, 15, No. 1, 1-13. [doi: 10.1680/gein.2008.15.1.1]

\section{INTRODUCTION}

Veneer cover soil systems in containment facilities such as landfills, dams and liquid impoundments involve geosynthetic-soil layers. These can consist of either single or multiple layers of geosynthetics and soils. The main design criterion for veneer cover soil is to ensure that no slippage occurs between the layers during and following construction. Instability can be caused by the weight of the cover soil, equipment loadings, seepage forces within the cover soil, and/or seismic forces in seismically active areas. Numerous researchers have introduced and adopted different methods to improve stability, such as tapered cover soil, toe berms, reinforcement and modifying the geometry of the facility (Koerner and Hwu 1991; Koerner and Soong 2005). Stability assessment has included using simple limit equilibrium wedge methods for preliminary design and relatively complex finite element methods for forensic studies.

In this study, the limit equilibrium wedge method with modified formulations from Giroud et al. (1995) is used to produce design charts. A design chart provides an explicit graphical solution, which can be useful for preliminary design. It depicts the behaviour of a system if a significant design parameter changes, and thus assists in determining the optimum design. A deterministic design chart is created as a first step, and this is developed to produce a reliability-based design chart that incorporates the uncertainties in the significant parameters controlling veneer cover soil stability. Examples are included to demonstrate application of the charts, and to highlight the significance of uncertainty in design.

\section{MODIFIED LIMIT EQUILIBRIUM WEDGE METHOD}

Figure 1 illustrates two wedges that are considered to act along a cover soil slope. These are used to formulate the factor of safety against sliding mode of failure. Unlike most researchers, who defined the factor of safety in the limit equilibrium two-wedge method as the ratio between the available and mobilised values of the strength parameters, Giroud et al. (1995) defined the factor of safety in 


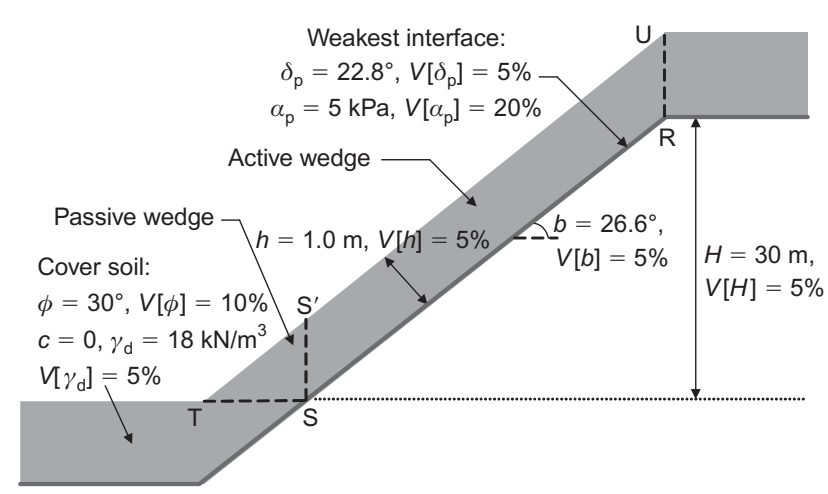

Figure 1. Schematic diagram of veneer cover soil showing base case values for design parameters used in examples

the two-wedge method as the ratio of the resistance over the driving forces. Their proposed formulations are adopted in this study because they are computationally simple and reduce geometric manipulation. However, their formulations have been modified so that the terms are expressed in terms of interface shear strengths rather than individual derived interface shear parameters of friction angle and adhesion. This modification allows more flexibility in choosing lining materials with different strength characteristics.

The modified formulations inherit limitations and assumptions similar to those asserted in Giroud et al. (1995). They include uniform thickness of the cover soil, dry conditions, which assume that the drainage system is working efficiently, and no other slippage except at the weakest interface. However, the approach developed in this study can be extended to take account of tapered cover soil and/or submergence conditions, but this involves creating additional design charts for specific cases.

\subsection{Definitions and formulations}

Symbols used in the formulations are defined in the schematic diagram of veneer cover soil shown in Figure 1. Other symbols used are defined in the Notations section. Formulations used to produce the design charts are derived using force diagrams similar to the ones given in Giroud et al. (1995). The geometry and forces acting on the active and passive wedges, which are denoted with the subscripts ' $A$ ' and 'P', respectively, are shown in Figures 2 and 3. The resultant force $(E)$ acting between the wedges is assumed to act parallel to the slope inclination. All forces used in the formulations are force per unit length perpendicular to the plane of the considered figures and diagrams.

The force diagram for the passive wedge is solved first to obtain $E_{\mathrm{P}}$. The weight of the passive wedge and the contribution from cover soil cohesion are given as follows.

$$
\begin{aligned}
W_{\mathrm{P}} & =\frac{\gamma h^{2}}{2 \sin b \cos b} \\
C_{\mathrm{P}} & =\frac{c h}{\sin b}
\end{aligned}
$$

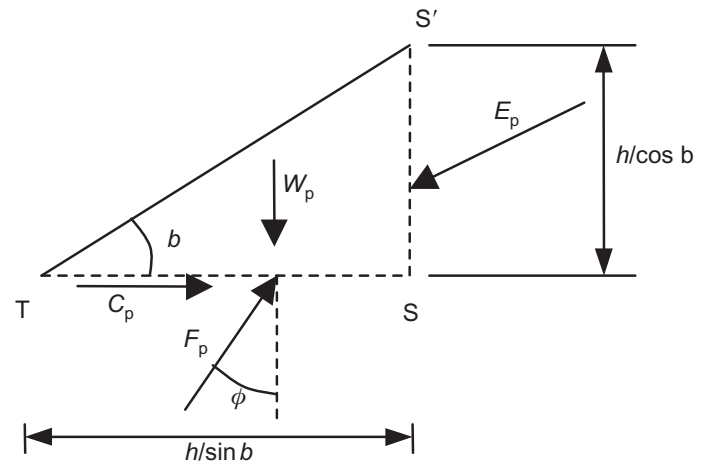

(a)

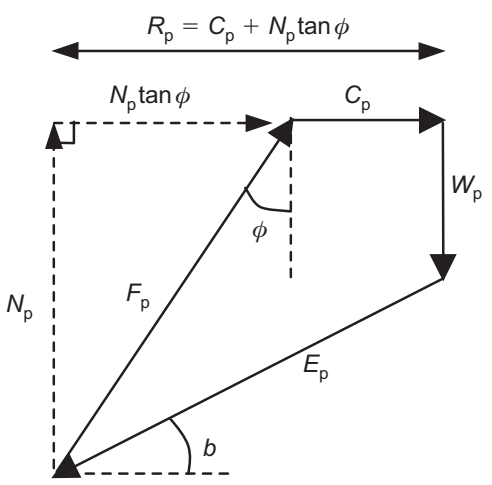

(b)

Figure 2. Passive wedge: (a) geometry and force; (b) force diagram (after Giroud et al. 1995). Note: Force diagram is not closed, which indicates that resistance forces are greater than driving forces, thus yielding FS $>1$

$N_{\mathrm{P}}$ in Equation 3 is obtained by solving the forces in the vertical direction.

$$
N_{\mathrm{P}}=W_{\mathrm{P}}+E_{\mathrm{P}} \sin b
$$

Substituting $W_{\mathrm{P}}$ into and solving the forces acting in the horizontal direction yields Equation 4 for $E_{\mathrm{P}}$.

$$
E_{\mathrm{P}} \cos b=W_{\mathrm{P}} \tan \phi+E_{P} \sin b \tan \phi+C_{\mathrm{P}}
$$

$E_{\mathrm{P}}$ is then finally resolved to Equation 5 by substituting Equations 1 and 2 into Equation 4.

$$
E_{\mathrm{P}}=\frac{(c h / \sin b)+\left(\gamma_{\mathrm{d}} h^{2} / 2 \sin b \cos b\right) \tan \phi}{\cos b-\sin b \tan \phi}
$$

Considering the active wedge force diagram (Figure 3), $W_{\mathrm{A}}$ and $C_{\mathrm{A}}$ are computed as follows.

$$
\begin{aligned}
W_{\mathrm{A}} & =\frac{\gamma_{\mathrm{d}} H h}{\sin b} \\
C_{\mathrm{A}} & =\frac{\alpha H}{\sin b}
\end{aligned}
$$

$N_{\mathrm{A}}$ in Equation 8 is then acquired by solving the force diagram in the direction perpendicular to the slope inclination. 


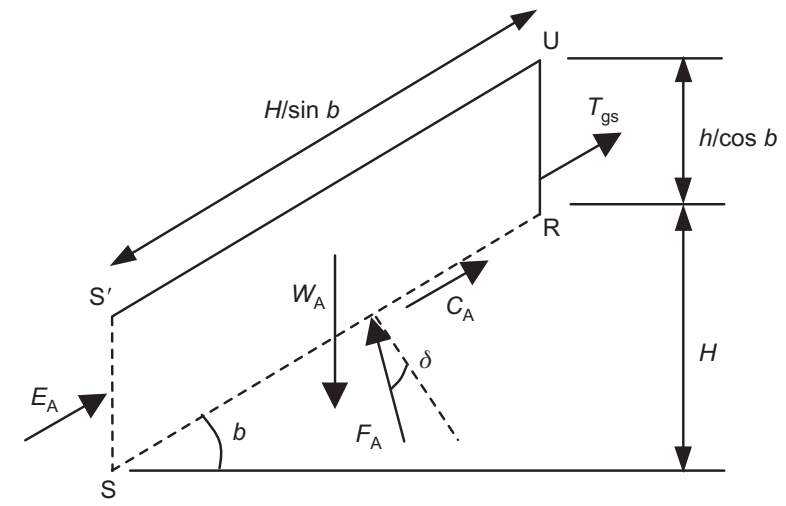

(a)

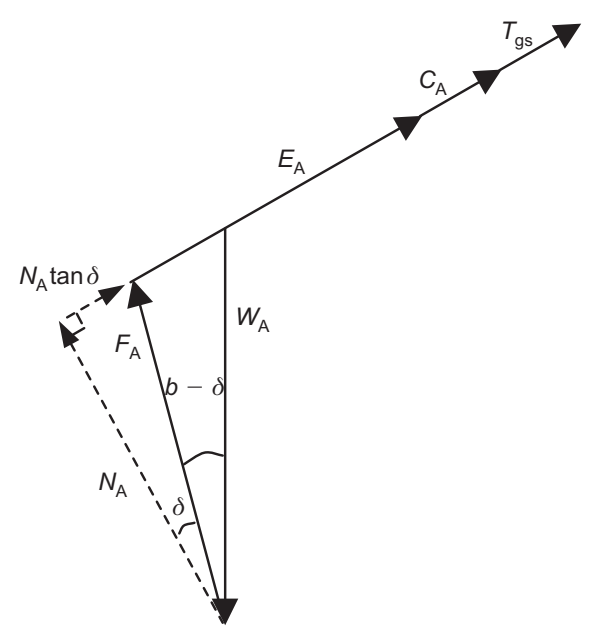

(b)

Figure 3. Active wedge: (a) geometry and force; (b) force diagram (after Giroud et al. 1995)

$$
N_{\mathrm{A}}=W_{\mathrm{A}} \cos b=\frac{\gamma_{\mathrm{d}} H h}{\sin b} \cos b
$$

Finally, the following factor of safety against sliding, $\mathrm{FS}$, is formulated as the ratio between the resisting $\left(F_{\mathrm{R}}\right)$ and driving $\left(F_{\mathrm{D}}\right)$ forces acting on the active wedge in the direction parallel to the slope inclination.

$$
\mathrm{FS}=\frac{F_{\mathrm{R}}}{F_{\mathrm{D}}}=\frac{E_{\mathrm{A}}+C_{\mathrm{A}}+N_{\mathrm{A}} \tan \delta+T_{\mathrm{gs}}}{W_{\mathrm{A}} \sin b}
$$

Resolving for FS by substituting Equations 5 to 8 into Equation 9 yields

$$
\begin{aligned}
\mathrm{FS}= & \frac{\alpha+\gamma_{\mathrm{d}} h \cos b \tan \delta}{\gamma_{\mathrm{d}} h \sin b} \\
& +\frac{c+\left(\gamma_{\mathrm{d}} h / 2 \cos b\right) \tan \phi}{\gamma_{\mathrm{d}} H \sin b(\cos b-\sin b \tan \phi)} \\
& +\frac{T_{\mathrm{gs}}}{\gamma_{\mathrm{d}} H h}
\end{aligned}
$$

$$
\mathrm{FS}=\frac{\tau_{\mathrm{IN}}}{\gamma_{\mathrm{d}} h \sin b}+\frac{\tau_{\text {soil }}}{\gamma_{\mathrm{d}} H \sin b(\cos b-\sin b \tan \phi)}+\frac{T_{\mathrm{gs}}}{\gamma_{\mathrm{d}} H h}
$$

where

$$
\begin{aligned}
\tau_{\mathrm{IN}} & =\alpha+\gamma_{\mathrm{d}} h \cos b \tan \delta \\
\tau_{\text {soil }} & =c+\frac{\gamma_{\mathrm{d}} h}{2 \cos b} \tan \phi
\end{aligned}
$$

In order to reduce the number of variables incorporated in the design charts, $T_{\mathrm{gs}}$ is not considered, which is a conservative assumption, and hence is on the safe side. Moreover, it is good practice to minimise tensile stresses in non-reinforcing geosynthetics such as geomembranes and geotextiles.

\subsection{Modification to FS formulation for use in design charts}

To avoid infinite values of calculated FS (e.g. $\phi=60^{\circ}$ and $\left.\mathrm{b}=30^{\circ}\right)$, the denominator of the second term $\left(D_{2}\right)$ in Equation 11 is maximised with slope inclination as follows, which results in a conservative FS.

$$
\frac{\mathrm{d} D_{2}}{\mathrm{~d} b}=0
$$

As a first step, $D_{2}$ is generalised to extricate the equation from the effect of cover soil cohesion by introduction of the $R$ factor as follows.

$$
D_{2}^{\prime}=\gamma_{\mathrm{d}} H \sin b\left(\cos b-R \frac{\sin ^{2} b}{\cos b}\right)
$$

where $R=\tan \phi / \tan b$.

The following approximation is obtained by differentiating $D_{2}^{\prime}$ of Equation 15 with slope inclination and solving Equation 14.

$$
b=\sin ^{-1}\left\{\left[\frac{(3 R+3)-\sqrt{(3 R+3)^{2}-4(2 R+2)}}{2(2 R+2)}\right]^{0.5}\right\}
$$

A chart of maximised values for the denominator of the second term in Equation 11 is illustrated in Figure 4. In a sensitivity analysis, the modification yields differences of less than 0.05 when compared with FS values calculated using the original formulation. However, the difference of FS between the exact solution and using the modification is insignificant only for $\phi$ and $c$ not greater than $40^{\circ}$ and $5 \mathrm{kPa}$, respectively, slope inclinations between $15^{\circ}$ and $32^{\circ}, \gamma_{\mathrm{d}}$ between 17 and $20 \mathrm{kN} / \mathrm{m}^{3}$, and at any landfill height and cover soil thickness. When the maximised value for the denominator of second term in Equation 11 is used, any values of the parameters that fall outside these ranges may result in lower FS values than using the exact 


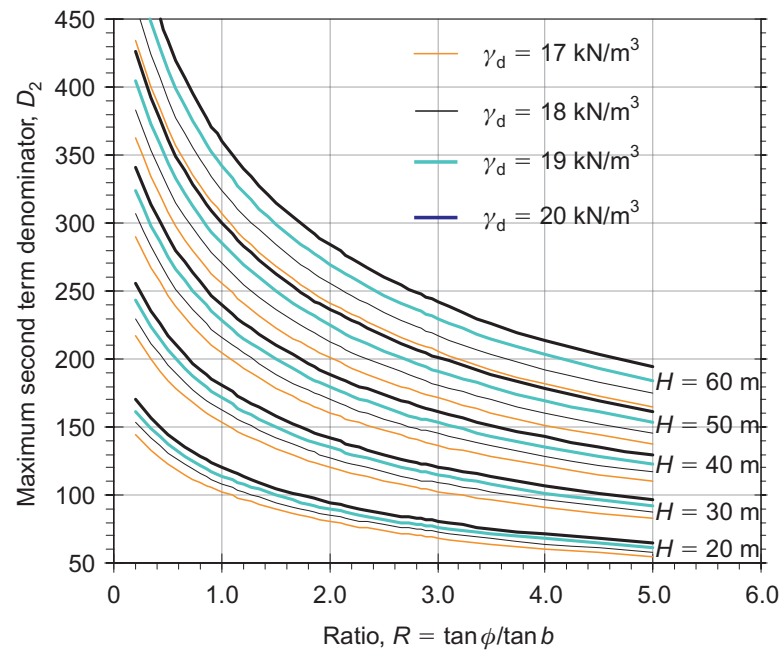

Figure 4. Maximum values for denominator of term 2 in Equation 11

solution, and therefore these factors of safety will be conservative.

\section{DEVELOPMENT OF DETERMINISTIC DESIGN CHART}

\subsection{Sensitivity analysis for deterministic design chart}

To produce a deterministic design chart, a sensitivity study is conducted to evaluate the most significant parameters for the veneer stability model. The sensitivity of the input parameters is investigated using Tornado charts. A Tornado chart depicts the percentage of change in the performance measure $\left(\partial \mu_{Y} / \mu_{Y}\right)$ such as FS, for a percentage change in input parameter $\left(\partial \mu_{X i} / \mu_{X i}\right)$ about its mean value as follows:

$$
S_{i}=\frac{\partial \mu_{Y} / \mu_{Y}}{\partial \mu_{X i} / \mu_{X i}}=\left.\frac{\partial Y}{\partial X i}\right|_{\mu_{\bar{X}}} \frac{\mu_{X i}}{\mu_{Y}}
$$

Positive $S_{i}$ values indicate a beneficial contribution in increasing the performance measure with increasing value of the input parameter, and negative values imply the opposite. Figure 5a shows a Tornado chart, using the partial derivatives shown in the Appendix, evaluated at the base case values stated in Table 1 . Figure $5 \mathrm{~b}$ demonstrates

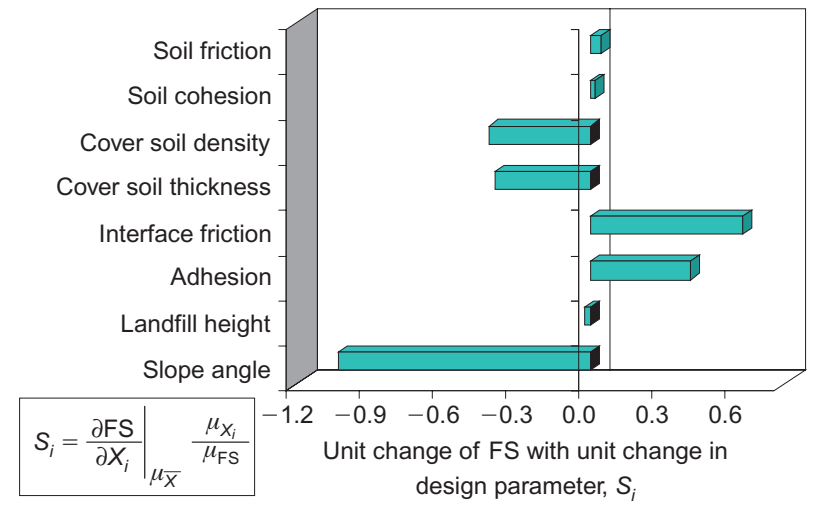

(a)

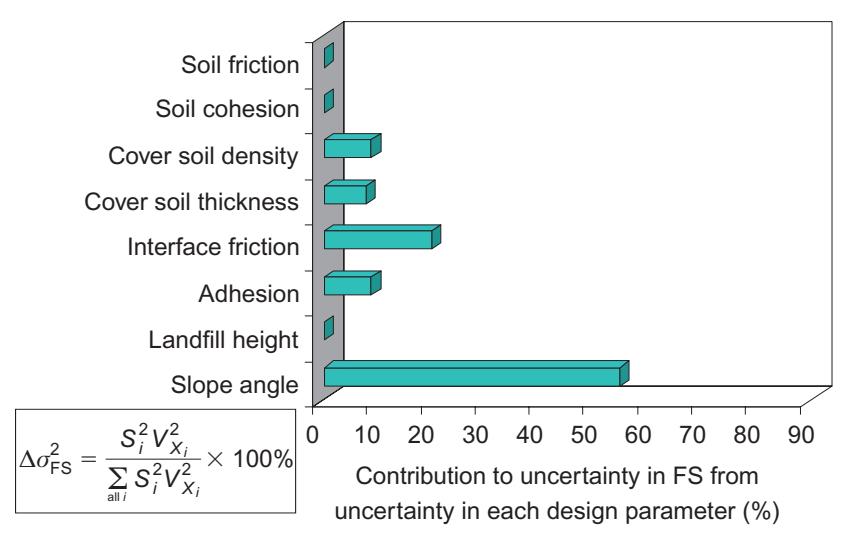

(b)

Figure 5. Tornado charts to illustrate sensitivity of: (a) input parameters to change in FS; (b) contribution of input parameter uncertainty to uncertainty in FS

the percentage contribution of uncertainty in input parameters to uncertainty in FS, computed using the following equation.

$$
\Delta \sigma_{\mathrm{FS}}^{2}=\frac{S_{i}^{2} V_{X i}^{2}}{\sum_{\text {all } i} S_{i}^{2} V_{X i}^{2}} \times 100 \%
$$

where $V_{X i}$ is the coefficient of variation for an input parameter.

Additionally, each design parameter is varied in its normal range stated in Table 1, with other parameters kept at the base case values. The parameters that change FS by less than $5 \%$ of the target FS of 1.5 within their normal

\begin{tabular}{|c|c|c|c|c|c|c|c|c|}
\hline Parameters & $H(\mathrm{~m})$ & $b$ (degrees) & $\gamma_{\mathrm{d}}\left(\mathrm{kN} / \mathrm{m}^{3}\right)$ & $\phi$ (degrees) & $c(\mathrm{kPa})$ & $h(\mathrm{~m})$ & $\delta$ (degrees) & $\alpha(\mathrm{kPa})$ \\
\hline Base value & 30 & 26.6 & 18 & 30 & 0 & 1 & 22.8 & 5 \\
\hline$H$ & $20-50$ & 26.6 & 18 & 30 & 0 & 1 & 22.8 & 5 \\
\hline$b$ & 30 & $15-35$ & 18 & 30 & 0 & 1 & 22.8 & 5 \\
\hline$\gamma_{\mathrm{d}}$ & 30 & 26.6 & $16-20$ & 30 & 0 & 1 & 22.8 & 5 \\
\hline$\phi$ & 30 & 26.6 & 18 & $25-45$ & 0 & 1 & 22.8 & 5 \\
\hline$c$ & 30 & 26.6 & 18 & 30 & $0-10$ & 1 & 22.8 & 5 \\
\hline$h$ & 30 & 26.6 & 18 & 30 & 0 & $0.2-2$ & 22.8 & 5 \\
\hline$\delta$ & 30 & 26.6 & 18 & 30 & 0 & 1 & $15-35$ & 5 \\
\hline$\alpha$ & 30 & 26.6 & 18 & 30 & 0 & 1 & 22.8 & $0-10$ \\
\hline
\end{tabular}

Table 1. Design values for deterministic parametric study (bold values are varied typical range) 
ranges (i.e. $1.425<\mathrm{FS}<1.575$ ) are considered to be insignificant. Based on the Tornado charts and additional sensitivity analysis outputs depicted in Figure 6, it is found that the critical parameters are interface shear strength parameters $\alpha$ and $\delta$, slope inclination $b$ and cover soil thickness $h$. Insignificant parameters include the friction angle $\phi$ and cohesion $c$ of the cover soil, the height of the landfill facility, $H$, and the dry unit weight of cover soil, $\gamma_{\mathrm{d}}$. To create the design charts in subsequent analyses, insignificant parameters are kept at their constant mean base case values. It has to be highlighted that the insignificant parameters have little influence on the FS because the geometry of the landfill of the study is a dry uniform slope. Other types of geometry, such as a tapered slope and saturation conditions, may yield different outcomes.

\subsection{Deterministic design chart}

Figure 7 depicts deterministic design charts of veneer cover stability for a landfill height of $30 \mathrm{~m}$ and cover soil thickness $h$ of $0.5 \mathrm{~m}$ and $1 \mathrm{~m}$, respectively. The curves in the design chart are created to achieve FS of 1.5 for any combination of maximum slope inclination or minimum required interface shear strength at the weakest interface. Applications of the deterministic design chart are illustrated below. The deterministic design chart enables the selection of different types of geosynthetic as lining materials based on the required interface shear strength for stability. Therefore suitable and economical geosynthetic materials can be selected to form a liner that will satisfy the minimum requirement of safety against sliding. Additionally, landfill capacity can be optimised by adopting the highest possible slope angle that satisfies safety

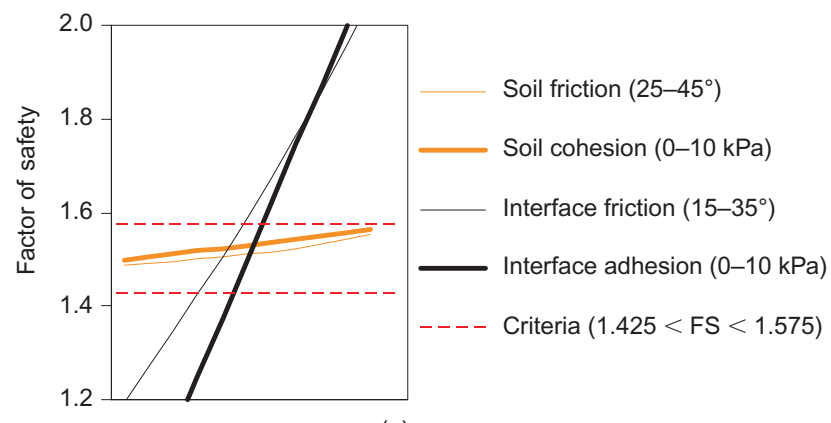

(a)

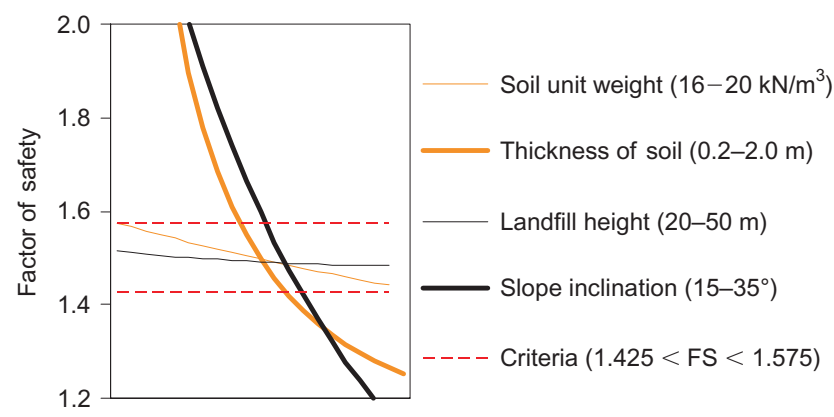

(b)

Increasing value of input parameter within stated range

Figure 6. Sensitivity study of (a) positive and (b) detrimental input parameters on FS

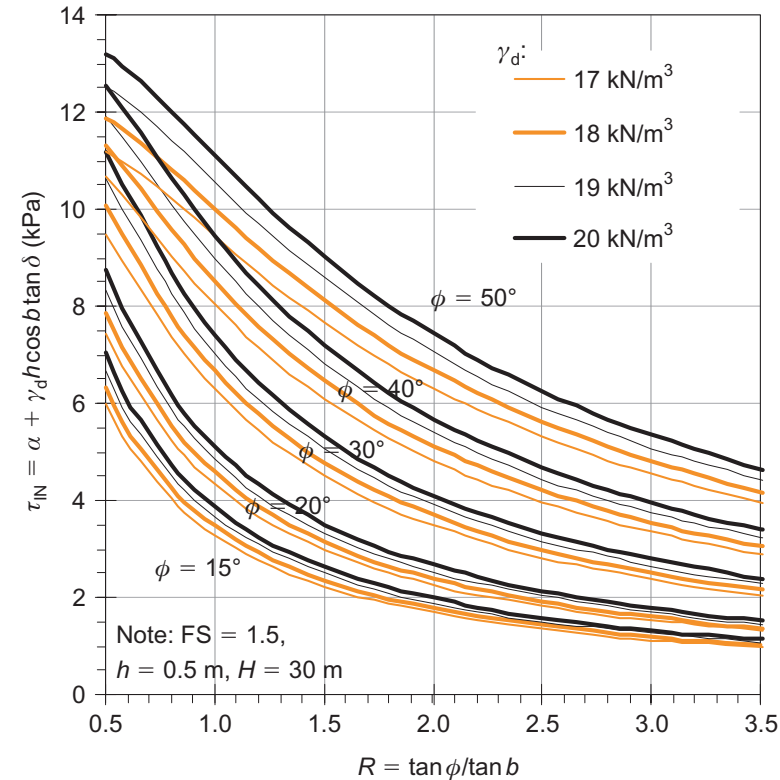

(a)

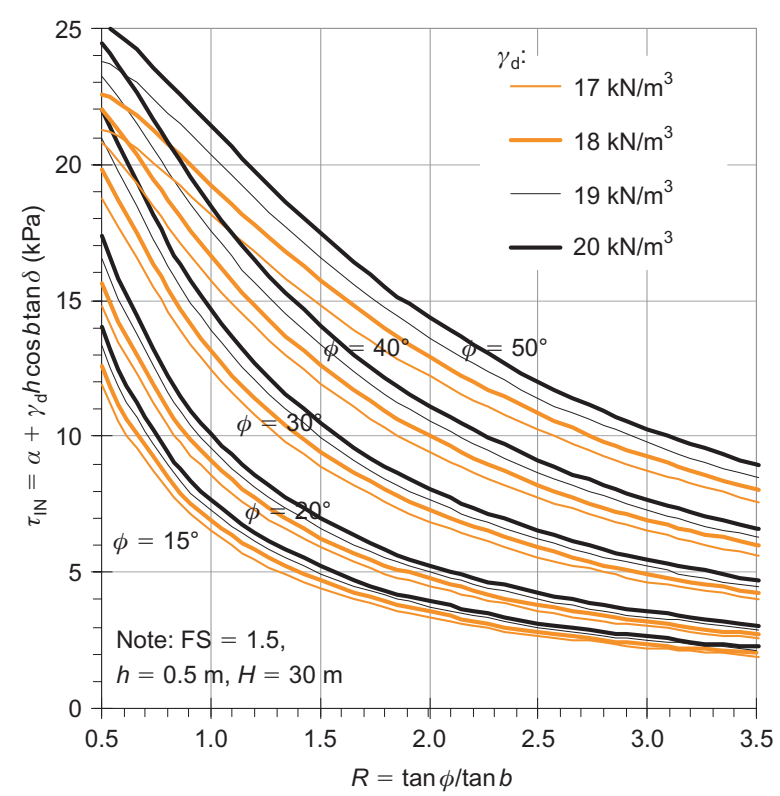

(b)

Figure 7. Deterministic design charts for sliding stability with: (a) $h=0.5 \mathrm{~m}$; (b) $h=1.0 \mathrm{~m}$

against sliding, given that the site and lining materials have been selected. However, one major limitation of the deterministic design chart is that it does not consider the uncertainty associated with each design parameter, and therefore the resulting FS of 1.5 is ambiguous.

\subsection{Application and examples}

Example 1: Selection of liner materials

Given the veneer cover configuration in Figure $1, R$ is calculated as 1.15, which results in the required interface shear strength $\tau_{\mathrm{IN}}$ of $11.8 \mathrm{kPa}$ using Figure $7 \mathrm{~b}$. Examples of interface shear strength parameters that satisfy $\tau_{I N}$ of $11.8 \mathrm{kPa}$ to achieve a factor of safety of 1.5 are stated in Table 2. Therefore any geosynthetic and soil materials that have the combination of interface shear parameters stated 
Table 2. Interface shear strength parameters to achieve $\tau_{\mathrm{IN}}=11.8 \mathrm{kPa}$

\begin{tabular}{|l|c|}
\hline$\alpha(\mathrm{kPa})$ & $\delta$ (degrees) \\
\hline 0 & 36.2 \\
2 & 31.2 \\
5 & 22.8 \\
10 & 6.3 \\
\hline
\end{tabular}

in Table 2 are suitable as lining materials, to satisfy stability against sliding.

Example 2: Optimising landfill capacity

A few iterations are required in order to obtain the maximum allowable slope angle for the landfill that satisfies FS of 1.5 against sliding. The iteration steps are as follows.

1. Assume an initial value for $\tau_{\mathrm{IN}}$.

2. Acquire $R$ from Figure 7 and calculate $b$.

3. Calculate $\tau_{\mathrm{IN}}$ using Equation 12 .

4. Compare $\tau_{\mathrm{IN}}$ calculated in step 3 with the assumed value of $\tau_{\mathrm{IN}}$ in step 1 and repeat the process until the two values converge.

Given a similar cover soil as in Example 1, and given that the weakest interface in the lining system has $\alpha$ and $\delta$ of $5 \mathrm{kPa}$ and $20^{\circ}$ respectively, assume the initial value for $\tau_{\mathrm{IN}}$ is $10 \mathrm{kPa} . R$ is obtained as 1.4 using Figure 7 , and subsequently $b$ is calculated as $22.4^{\circ}$. $\tau_{\mathrm{IN}}$ is then calculated using Equation 12, and the new value is $11.06 \mathrm{kPa}$. This value is not equal to the initial assumed $\tau_{\mathrm{IN}}$, which is $10 \mathrm{kPa}$. The process is repeated until $\tau_{\mathrm{IN}}$ from consecutive iterations converges. Three iterations are needed for this example, as demonstrated in Table 3. Therefore the maximum allowable slope angle for the landfill to ensure safety against sliding is $24.5^{\circ}$.

\section{DEVELOPMENT OF RELIABILITY- BASED DESIGN CHART}

Most uncertainty and variability are dealt with statistically, which involves estimation of expected values and standard deviations of the design parameters taken as random variables. In probabilistic or reliability methods, uncertainties reflected in the input parameters are evaluated statistically to produce corresponding uncertainties in the

Table 3. Iteration process to obtain maximum slope angle given that $\alpha=5 \mathrm{kPa}$ and $\delta=20^{\circ}$

\begin{tabular}{|l|c|c|c|c|}
\hline Iteration & Initial $\tau_{\mathrm{IN}}(\mathrm{kPa})$ & $R$ & $\mathrm{~b}$ (degrees) & $\tau_{\mathrm{IN}}(\mathrm{kPa})$ \\
\hline 1 & $10^{\mathrm{a}}$ & 1.40 & 22.4 & 011.06 \\
2 & 11.06 & 1.25 & 24.8 & 0.95 \\
3 & 10.95 & 1.21 & 24.5 & 10.96 \\
\hline
\end{tabular}

${ }^{\text {a Assumed. }}$. performance function such as factor of safety. The value of an input parameter or random variable is represented using a probability distribution. A probability distribution function states all the possible values that a random variable can take and their corresponding probability of occurrence. Statistical moments of a variable, namely mean and standard deviation, are usually required to define a distribution or a probability density function.

The reliability-based design chart presented in this paper considers uncertainty only in values of the design parameters. Besides the errors that might occur during laboratory testing, uncertainty also occurs in deciding the mobilised interface shear strength to adopt for design. Table 4 states the coefficient of variations of interface shear strength parameters between a textured HDPE geomembrane (TGM-NWGT) against a nonwoven geotextile, and between the textured geomembrane against Mercia Mudstone (TGM-fines), obtained from a laboratory repeatability test programme (Sia and Dixon 2007). Variations of the interface shear strength parameters are small compared with a compiled global database from a literature review, in which the variation reached up to $40 \%$. Additional information on the repeatability test programme and the global database are presented by Sia and Dixon (2007); based on the reported variability, the interface shear strength parameters considered for the reliability-based design chart are varied from $5 \%$ up to $40 \%$.

Before producing a reliability-based design chart, a sensitivity study has been conducted to find out which uncertain inputs will significantly affect the performance measure of reliability (e.g. reliability index or probability of failure), and hence which should be varied within their typical range.

\subsection{Additional performance measure}

Probability of failure $\left(P_{\mathrm{f}}\right)$ in reliability analysis is analogous to factor of safety in a deterministic approach. Instead of a ratio of 'failed' trials (i.e. FS less than 1.0) to the total number of trials, the probability of failure $\left(P_{\mathrm{f}}\right)$ is calculated as the area underneath the distribution of reliability index, for which FS is less than 1.0 and is assumed normally distributed. Reliability index and probability of failure are defined in Equations 19 and 20, respectively.

Table 4. Coefficient of variation $V$ for TGM-NWGT and TGM-Fines interfaces for applied normal stresses not greater than $50 \mathrm{kPa}$ (rounded up to nearest 1\%)

\begin{tabular}{|l|c|c|}
\hline & $V[\delta](\%)$ & $V[\alpha](\%)$ \\
\hline TGM-NWGT & & \\
Peak & 7 & 13 \\
Large displacement & & 15 \\
TGM-Fines & 10 & 19 \\
Peak & 10 & 25 \\
Large displacement & \\
\hline
\end{tabular}




$$
\begin{aligned}
& \beta=\frac{\mu_{\mathrm{FS}}-1}{\sigma_{\mathrm{FS}}} \\
& P_{\mathrm{f}} \cong \Phi(-\beta)
\end{aligned}
$$

$\mu_{\mathrm{FS}}$ and $\sigma_{\mathrm{FS}}$ are the mean and standard deviation of factor of safety, which is assumed to be normally distributed, and $\Phi$ is a standard normal distribution function. In sensitivity analysis $\mu_{\mathrm{FS}}$ is calculated using Equation 11, and evaluated for a base case value of each input parameter; $\sigma_{\mathrm{FS}}$ is computed using a Taylor series approximation:

$$
\sigma_{\mathrm{FS}}^{2}=\sum\left[\sigma_{X i}^{2}\left(\frac{\partial \mathrm{FS}}{\partial X_{i}}\right)^{2}\right]
$$

Using the base case values shown in Figure $1, \mu_{\mathrm{FS}}$ and $\sigma_{\mathrm{FS}}$ are computed as 1.5 and 0.16 (i.e. $V[\mathrm{FS}]=10.7 \%$ ), respectively. For a target FS of 1.5 and its uncertainty in terms of coefficient of variation $(\mathrm{V})$ of $10 \%$, Figure 8 demonstrates that the assumption of normality for FS is

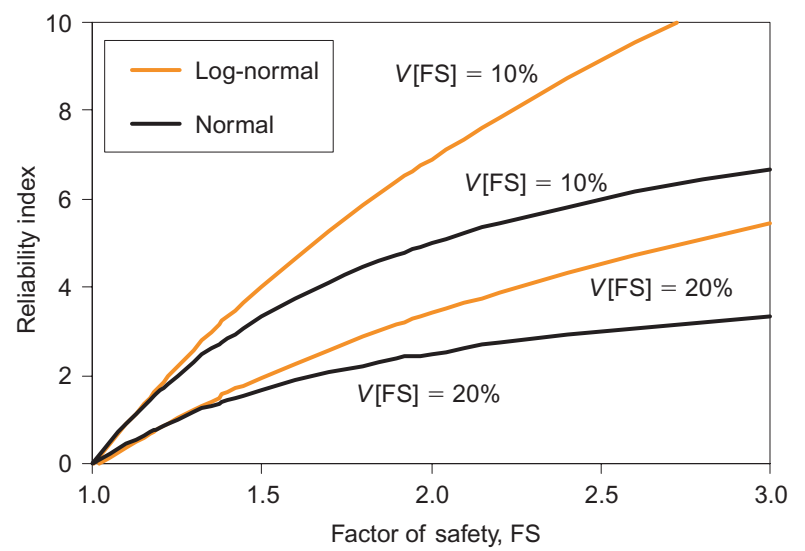

(a)

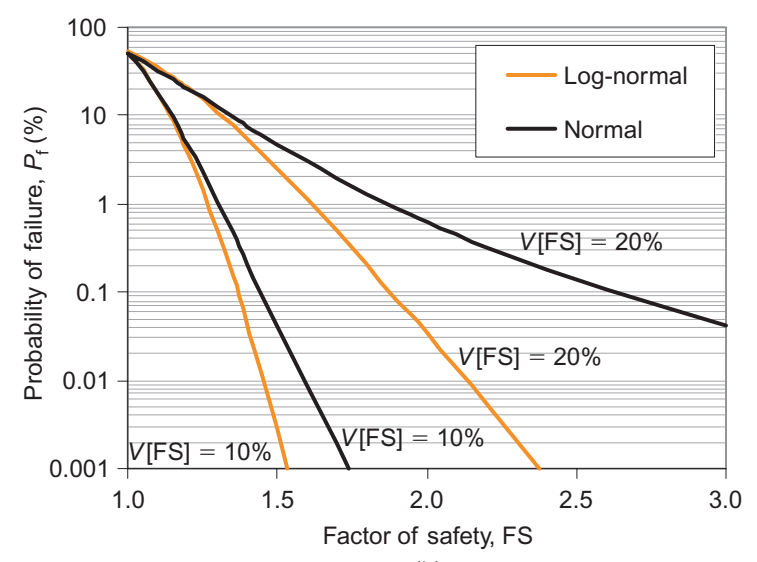

(b)

Figure 8. Comparison between normal and log-normal distributed FS on the safe side, as this assumption would result in a higher failure probability for similar FS and degree of uncertainty.

\subsection{Sensitivity analysis for reliability-based design chart}

Similar to the deterministic analysis, Tornado charts are used to investigate the sensitivity of mean and uncertainty of input parameters to the reliability index, $\beta$ ( $P_{\mathrm{f}}$ was not used, because it does not have a closed-form solution). For accuracy, the partial derivatives of $\beta$ with input parameters and their uncertainty in terms of standard deviation for Equation 17 are tabulated using Matlab version 6.5. The sensitivity measure $S_{i}$ is evaluated at the base case values given in Tables 1 and 5 for the mean and their uncertainty values, respectively. The equations accompanying the Tornado charts in Figures 10 and 11 are formulas used to compute the sensitivity values.

Figure 9 illustrates the percentage change in design parameters and their corresponding uncertainty to the percentage change in $\beta$. Based on Figure $9 \mathrm{~b}$, all uncertainty in the design parameters has a detrimental effect on the reliability index, as dictated by the negative values. Figure 10a demonstrates the percentage change in uncertainty of FS for a percentage change in the uncertainty of an input parameter, and Figure 10b shows the contribution of uncertainty in design parameters to uncertainty in the computed $\beta$. The ranking of significant parameters based on the change in $\beta$, FS or their corresponding uncertainty is observed to be dependent on both the mean and the degree of uncertainty in input parameters (in terms of standard deviation). However, it is found consistently that slope inclination, interface friction and adhesion, as well as their uncertainty, are the major design parameters to consider for the development of reliability-based design charts. However, the coefficient of variation for slope inclination was kept constant at $5 \%$, since its construction can be controlled (contractor allowable tolerance, which is stated in a contract) and is usually allowed to deviate by up to $2 \%$ (Sia 2007). Landfill height, cover soil friction and cohesion, as well as their uncertainties, are not significant parameters, and hence are kept at their base case values for development of the design chart. Cover soil thickness, soil density and their uncertainty have some influence, but are also adopted at base case values to limit the number of variables in the design chart. Nevertheless, different design charts could be created for different cover soil thicknesses and soil densities.

\subsection{Selection of target probability of failure}

During the development of a reliability-based design chart, the curves are generated such that the minimum interface

Table 5. Base case values of coefficient of variation $V$ for reliability-based veneer cover design sensitivity study

\begin{tabular}{|l|c|c|c|c|c|c|c|c|}
\hline Parameter & $V[H](\%)$ & $V[b](\%)$ & $V\left[\gamma_{\mathrm{d}}\right](\%)$ & $V[\phi](\%)$ & $V[c](\%)$ & $V[h](\%)$ & $V[\delta](\%)$ & $V[\alpha](\%)$ \\
\hline Base value & 5 & 5 & 5 & 10 & 10 & 5 & 5 & 20 \\
\hline
\end{tabular}




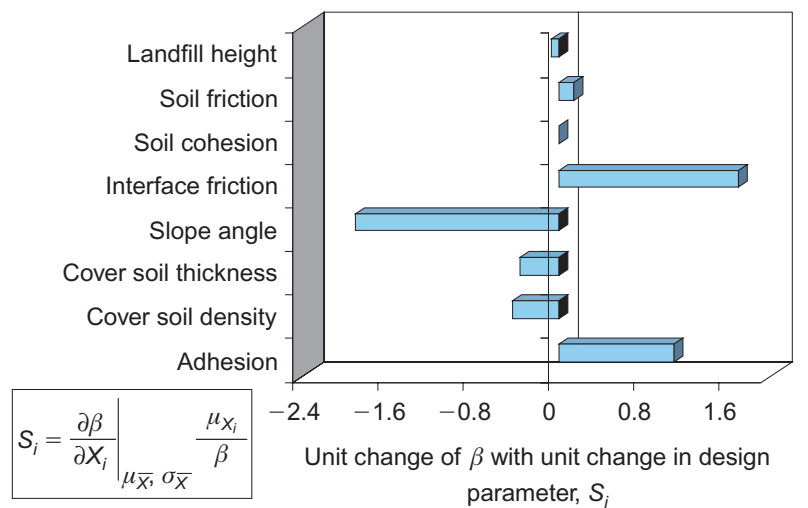

(a)

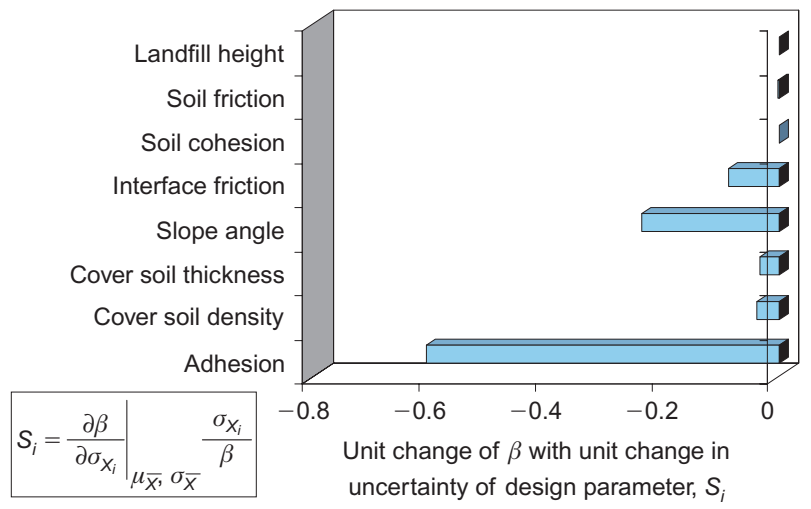

(b)

Figure 9. Tornado charts to illustrate sensitivity of (a) input parameters and (b) their uncertainty (i.e. expressed in terms of standard deviation) to change in reliability index

shear strength or maximum slope inclination can be estimated, which satisfy both the target probability of failure, $P_{\mathrm{ft}}$ and the required factor of safety. The values of $P_{\mathrm{ft}}$ are determined based on judgement using an existing scale of $\mathrm{P}_{\mathrm{ft}}$ that has been established in the literature and discussed by Dixon et al. (2006). Assuming that a landfill cover soil performed below average, based on USACE (1999), owing to construction equipment and loading, was exposed to moderate risk according to Gilbert (2001), and requires only minor repairs upon unsatisfactory performance conforming with Cole (1980), $P_{\mathrm{ft}}$ is estimated to be $1 \times 10^{-2}$, which is located between the annual probability of failure of mine slopes and foundations in Figure 11.

The assigned $P_{\mathrm{ft}}$ for the reliability-based design chart of veneer cover soil stability is higher than the recommended value of $5 \times 10^{-3}$ for 'typical' consequences ( $\leqslant$ US\$1 000000 ) for barrier function failure (Koerner 2002), between 'below' and 'above average' performance level given in USACE (1999), and classed as 'medium' degree of system redundancy if failure occurs (D'Hollander 2002). Sabatini et al. (2002) used a conservative $P_{\mathrm{ft}}$ value of $1 \times 10^{-4}$ for waste containment system stability analyses. The use of a value for $P_{\mathrm{ft}}$ that is higher than given in the literature could be compensated for by the use of relatively high degrees of uncertainty associated with the construction tolerances (e.g. $V[H], V[b]$ and $V[h])$ of $5 \%$ applied in the design chart, as expert elicitation has indicated that it is typically less than $5 \%$ in practice (Sia 2007).

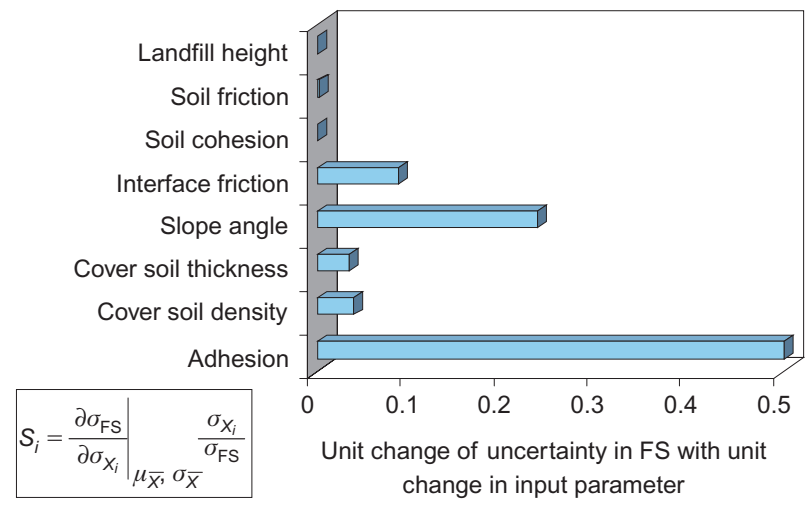

(a)

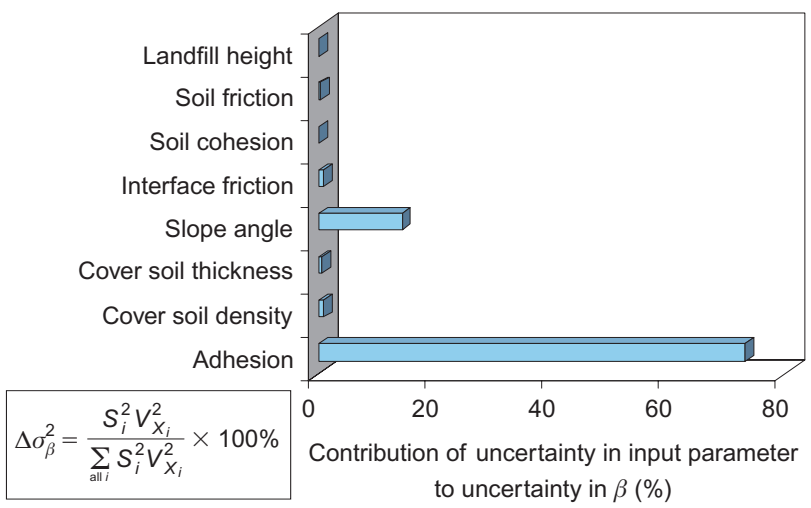

(b)

Figure 10. Tornado charts to illustrate sensitivity of: (a) uncertainty in input parameters to uncertainty in FS; (b) contribution of input parameters uncertainty to uncertainty in $\beta$ (i.e. uncertainty is expressed in terms of standard deviation)

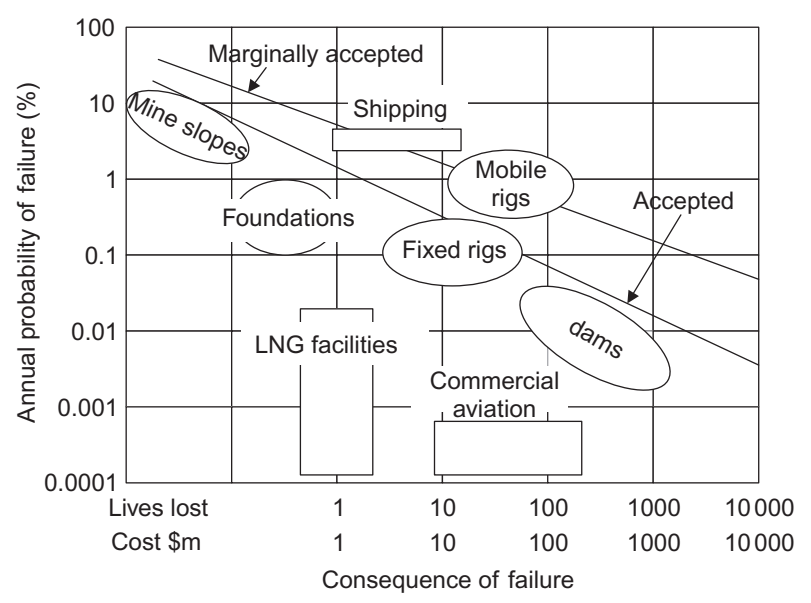

Figure 11. Empirical rates of failure for civil engineering facilities (after Baecher 1987)

\section{RELIABILITY-BASED DESIGN CHART}

Analyses to produce a reliability-based design chart were carried out in a spreadsheet with an Excel add-in, @RISK version 4.5, using Monte Carlo simulation. The coefficient of variation, $V$, for base case values is stated in Table 5 . The geometries of the veneer cover (i.e. $H, h$ and $b$ ) are assigned uniform distributions, which express equal chances of error from a lack of construction quality 
control and achievable construction tolerances. The cover soil properties are assigned normal distributions with variations in accordance to Duncan (2000), and the interface shear strength parameters are assumed to be lognormally distributed, as both parameters are usually positive in value for dry conditions. Alternatively, both parameters can be postulated as normally distributed, with distribution tails truncated at minimum and maximum plausible values (Sia and Dixon 2007). Both types of assumed distribution would yield similar outcomes (e.g. reliability index or probability of failure), because the variability of the interface shear strength parameters is relatively small.

The process to create a reliability-based design that satisfies FS of 1.5 and $P_{\mathrm{ft}}$ of $1 \times 10^{-2}$ is shown in Figure 12. Initially, $\delta$ to achieve FS of 1.5 is calculated using Equations 11 and 12 by assuming a value of $\alpha$, e.g. $0 \mathrm{kPa}$. The factor $R$ is also assumed, e.g. 0.2. The slope inclination can then be calculated, as $\phi$ is taken at the base case value of $30^{\circ}$. Similarly, other design parameters and their uncertainty are also assigned base case values. In each simulation FS is calculated for different values of the design parameters, which are randomly sampled based on their probability distribution using the Monte Carlo method. Subsequently, the distribution of FS shown in Figure 13 with its mean $\left(\mu_{\mathrm{FS}}\right)$ and standard deviation $\left(\sigma_{\mathrm{FS}}\right)$ is obtained after the simulation achieves convergence (i.e. changes in statistical moments of FS are less than $0.5 \%$ for subsequent simulations). The reliability index $\beta$ and corresponding failure probability $P_{\mathrm{f}}$ are calculated by assuming that FS is normally distributed. Steps 2 to 5 in Figure 12 are repeated for different values of $R$, ranging from 0.2 to 3.0. An example intermediary chart as shown in Figure 14 can then be plotted, and $R$ values corresponding to $P_{\mathrm{f}}$ of $1 \times 10^{-2}$ are obtained from the chart. The

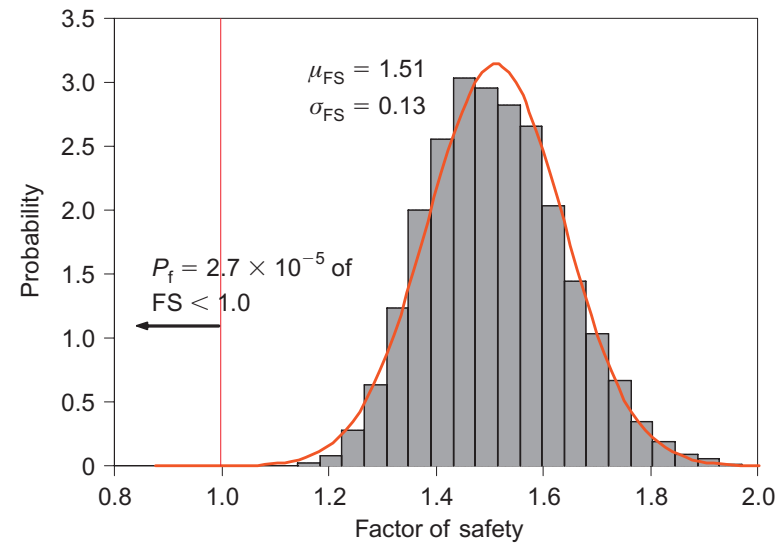

Figure 13. FS distribution after simulation for $\alpha$ of $5 \mathrm{kPa}$; $V[\alpha]=10 \%, V[\delta]=7 \%$ and $R=1.2$

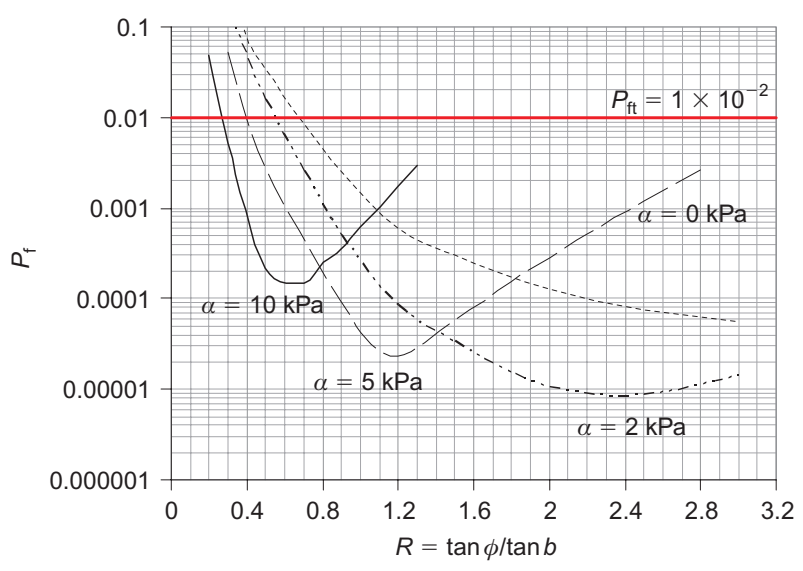

Figure 14. One of the intermediary charts used to estimate factor $R$ to satisfy $P_{\mathrm{f}}=1 \times 10^{-2}$. Note: $V[\alpha]=10 \%$, $V[\delta]=7 \%$

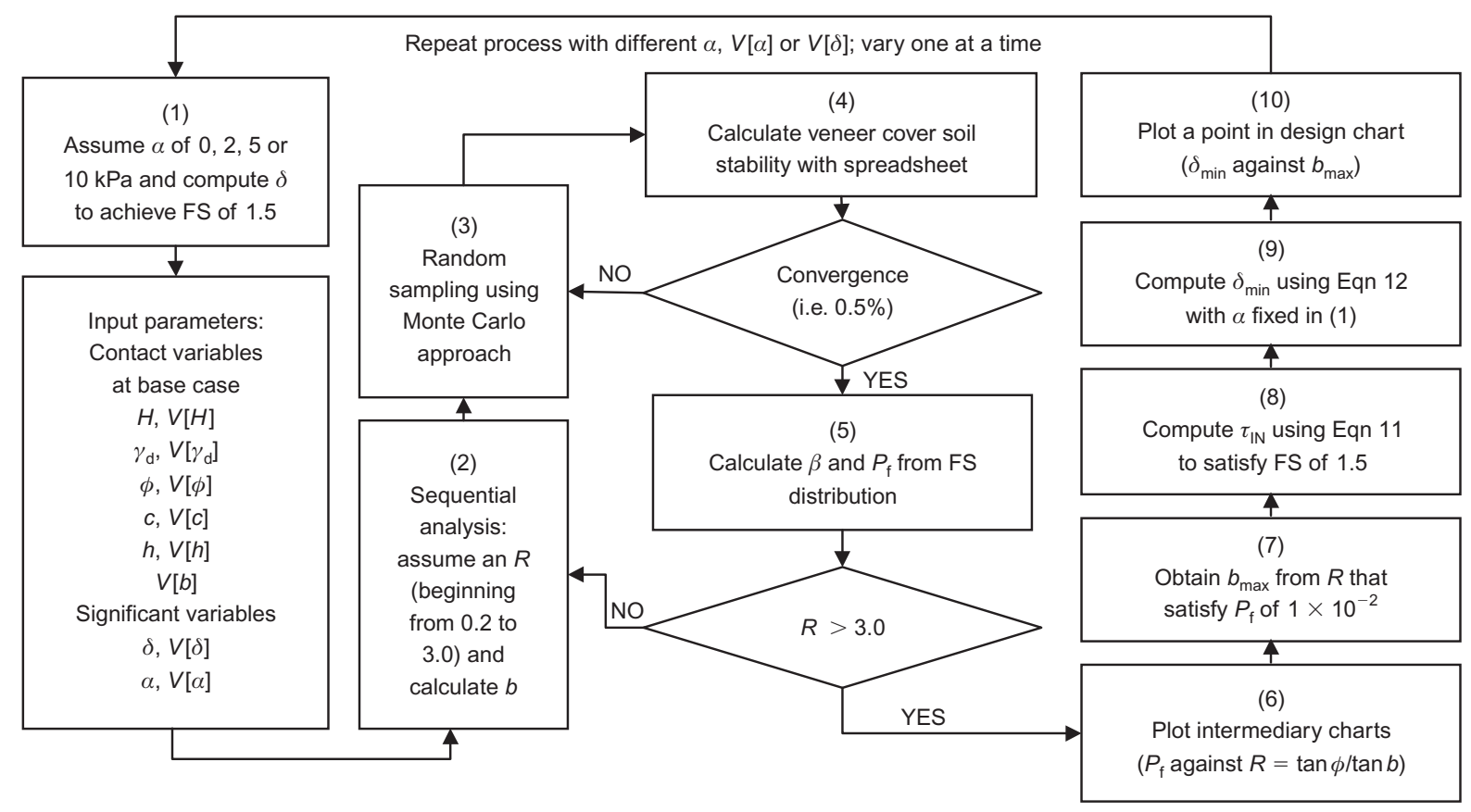

Figure 12. Flowchart illustrating one cycle of simulation to create reliability-based design chart that satisfies $P_{\mathrm{ft}}=1 \times 10^{-2}$ and $\mathrm{FS}=1.5$ 
resulting maximum slope angle $\left(b_{\max }\right)$ can be computed from the $R$ value (i.e. $\phi=30^{\circ}$ ), and $\tau_{\mathrm{IN}}$ and the minimum requirement for interface friction angle $\left(\delta_{\min }\right)$ to satisfy FS of 1.5 can also be calculated from Equations 11 and 12, respectively. The entire process outlined in Figure 12 is repeated for different combinations of $\alpha$ values of $0,2,5$ and $10 \mathrm{kPa}, V[\alpha]$ of $10 \%, 20 \%$ and $40 \%$ or $V[\delta]$ ranging from $5 \%$ to $40 \%$, while maintaining other insignificant input parameters at their base case values. The reliabilitybased design chart for veneer cover soil stability illustrated in Figure 15 can finally be plotted. It expresses the relationship between $\delta_{\min }$ and $b_{\max }$ to achieve FS of 1.5 and $P_{\mathrm{f}}$ of $1 \times 10^{-2}$ for the specific slope geometry and cover soil properties.

\subsection{Application of reliability-based design chart}

The reliability-based design chart shown in Figure 15 can be used to find the minimum interface shear strength parameters to achieve FS of 1.5 , in addition to satisfying the failure probability of $1 \times 10^{-2}$ for the associated uncertainty in the design parameters. Additionally, the chart can be used to find the maximum slope angle for veneer cover, given that the strength parameters and their uncertainties are known (e.g. from laboratory testing).

The four dotted lines extending almost diagonally from left to right in Figure 15 represent interface adhesions of $0,2 \mathrm{kPa}, 5 \mathrm{kPa}$ and $10 \mathrm{kPa}$. These lines are drawn so that the corresponding interface friction angle at a certain slope angle will yield a factor of safety against sliding of 1.5. Other types of line, namely dark-coloured continuous lines, dashed lines and light-coloured continuous lines, express the uncertainty in the interface adhesion in terms of coefficient of variation. The dark-coloured continuous lines indicate the coefficient of variation for an interface adhesion of $10 \%$ with different magnitudes of uncertainty in interface friction angle. Similarly, the dashed lines record uncertainty for an interface adhesion of $20 \%$, and the light-coloured continuous lines designate the spread for an interface adhesion of $40 \%$. These lines connect the four dotted adhesion lines together, and any uncertainty that is beyond these lines in Figure 15 should not be interpolated. The percentages stated alongside the different types of line in Figure 15 indicate the uncertainty in the interface friction angle in terms of coefficient of variation.

For discussion, consider the coefficient of variation for an interface adhesion of $10 \%$, which is represented by the dark-coloured continuous lines. If common practice such as ignoring the interface adhesion is adopted, the maximum allowable uncertainty in the interface friction angle based on Figure 15 is $13.5 \%$. Any variability of interface friction angle greater than $13.5 \%$ will yield a higher probability of failure (i.e. greater than $1 \times 10^{-2}$ ). Similarly, if the interface adhesions are $2 \mathrm{kPa}, 5 \mathrm{kPa}$ and $10 \mathrm{kPa}$ with $10 \%$ associated uncertainty, the maximum allowable variations for interface friction angle are $24 \%$, $40 \%$ and $>40 \%$, respectively. Table 6 states the maximum allowable coefficients of variation for interface friction angle, given that the coefficients of variation for interface adhesion are $10 \%, 20 \%$ and $40 \%$. Interface properties that have variation less than stated in Table 6 will satisfy a probability of failure not greater than $1 \times 10^{-2}$. The term 'NS' indicates that the interface friction angle should be

Table 6. Maximum allowable $V[\delta](\%)$ for interface adhesion of $0,2 \mathrm{kPa}, 5 \mathrm{kPa}$ and $10 \mathrm{kPa}$ and $V[\alpha]$ of either $10 \%, 20 \%$ or $40 \%$ to achieve $P_{f}$ not greater than $1 \times 10^{-2}$

\begin{tabular}{|l|r|r|r|}
\hline \multirow{2}{*}{$\alpha(\mathrm{kPa})$} & \multicolumn{3}{|c|}{$V[\alpha](\%)$} \\
\cline { 2 - 4 } & 10 & 20 & 40 \\
\hline 0 & 13.5 & 13.5 & 13.5 \\
2 & 24.0 & 18.8 & 12.3 \\
5 & 40.0 & 17.0 & 7.0 \\
10 & $>40.0$ & 13.5 & $\mathrm{NS}^{\mathrm{a}}$ \\
\hline
\end{tabular}

${ }^{\mathrm{a}} \mathrm{NS}=$ not satisfied.

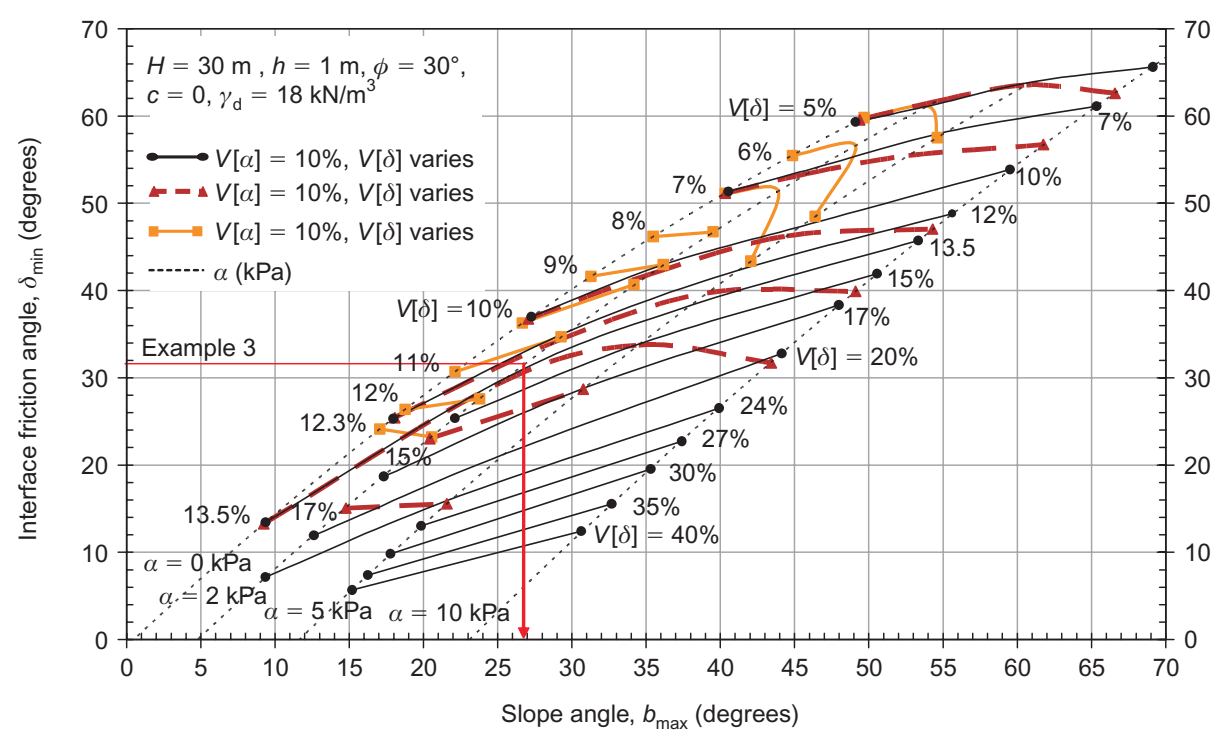

Figure 15. Reliability-based design chart for target FS of 1.5 and $P_{\mathrm{f}}$ of $1 \times 10^{-2}$ (after Sia and Dixon 2006) 
determined with certainty. Therefore, if interface adhesion is equal to or greater than $10 \mathrm{kPa}$ but the estimation is subjected to high uncertainty up to $40 \%$ or greater, the interface friction value must be ascertained to achieve a probability of failure not greater than $1 \times 10^{-2}$.

Given that the interface materials have been selected, the steps in utilising the reliability-based design charts are as follows.

1. Using Figure 15, determine the maximum slope angle for the landfill to achieve FS against sliding of 1.5 with the interface shear strength parameters obtained from a testing programme.

2. Pinpoint the intersection of the interface shear strength parameters and the maximum slope angle between two similar types of line, which indicate similar variation for interface adhesion. For example, the intersection point may be located between two dark-coloured continuous lines (i.e. $V[\alpha]=10 \%$ ), or between two dashed lines (i.e. $V[\alpha]=20 \%$ ), or between two light-coloured continuous lines (i.e. $V[\alpha]=40 \%)$.

3. Observe the numbers specifying the variation for interface friction angles for those two lines, and interpolate the variation from the intersection point.

4. The variation of interface shear strength parameters obtained or expected from laboratory tests should not be greater than that extracted in steps 2 and 3 , so that the probability of failure of less than $1 \times 10^{-2}$ is satisfied.

One limitation of the reliability-based design chart is that it fails to answer the question of how increase in FS is required to compensate for higher uncertainty in the interface shear parameters.

\section{Example 3: Using reliability-based design chart}

Adopting the same configuration of cover soil as used in Example 1, the lining materials constituting the weakest interface should be selected based on the combination of statistical moments asserted in Table 7 to achieve FS of 1.5 and $P_{\mathrm{ft}}$ of $1 \times 10^{-2}$. To obtain the values stated in Table 7, the steps described above are employed as follows.

1. Assuming that the interface adhesion and friction angle obtained from laboratory testing are $2 \mathrm{kPa}$ and

Table 7. Combination of statistical moments for weakest interface given that slope angle $b$ is $26.6^{\circ}$

\begin{tabular}{|l|c|c|c|c|}
\hline$\alpha(\mathrm{kPa})$ & $\delta$ (degrees) & \multicolumn{3}{|c|}{$V[\delta] \%$} \\
\cline { 3 - 5 } & & $V[\alpha]=10 \%$ & $V[\alpha]=20 \%$ & $V[\alpha]=40 \%$ \\
\hline 0 & 36.2 & 10.0 & 10.0 & 10.0 \\
2 & 31.2 & 13.3 & 13.0 & 11.5 \\
5 & 22.8 & 19.5 & 15.8 & $\mathrm{NS}$ \\
10 & 6.3 & $\mathrm{NS}^{\mathrm{a}}$ & $\mathrm{NS}$ & $\mathrm{NS}$ \\
\hline
\end{tabular}

${ }^{\mathrm{a}} \mathrm{NS}=$ not satisfied. $31.2^{\circ}$, the maximum slope angle for the cover soil to achieve FS against sliding of 1.5 using Figure 15 is $26.6^{\circ}$.

2. The intersection point of the interface shear strength parameters and the maximum slope angle are pinpointed between two similar types of line. For example, if the variation in interface adhesion $V[\alpha]$ is expected to be $10 \%$, the maximum variation for interface friction angle $V[\delta]$ to satisfy $P_{\mathrm{f}}$ of $1 \times 10^{-2}$ is located between two dark-coloured continuous lines. Similarly, if $V[\alpha]$ is expected to be $40 \%, V[\delta]$ is located between two light-coloured continuous lines.

3. For interface adhesion of $2 \mathrm{kPa}$ and $V[\alpha]$ of $10 \%$, the intersection point is located along the adhesion line (i.e. dotted line) for $2 \mathrm{kPa}$ and between two dark-coloured continuous lines with spreads in interface friction angle $V[\delta]$ of $12 \%$ and $13.5 \%$, as shown in Figure 15. However, if $V[\alpha]$ is expected to be $40 \%$, the intersection point is situated along the adhesion line for $2 \mathrm{kPa}$ and between two lightcoloured continuous lines with $V[\delta]$ of $11 \%$ and $12 \%$.

4. Therefore, by interpolating along the adhesion line for $2 \mathrm{kPa}$ and between two dark-coloured continuous lines for $V[\delta]$ of $12 \%$ and $13.5 \%$, the maximum allowable $V[\delta]$ to satisfy $P_{\mathrm{f}}$ of $1 \times 10^{-2}$ is $13.3 \%$. Similarly, if $V[\alpha]$ is $40 \%$, interpolating along the adhesion line of $2 \mathrm{kPa}$ and between two lightcoloured continuous lines yields a maximum allowable $V[\delta]$ of $11.5 \%$. Finally, the interface materials should be selected such that the interface shear strengths are greater than, but the associated variations are less than, the values stated in Table 7 in order to satisfy both the FS and $P_{\mathrm{ft}}$ criteria.

\subsection{Influence of $\boldsymbol{P}_{\mathrm{ft}}$ on reliability-based design chart} Comparison of curves to achieve $P_{\mathrm{ft}}$ of $1 \times 10^{-2}$ and $1 \times 10^{-4}$ is illustrated in Figure 16. If a stricter criterion is imposed on $P_{\mathrm{ft}}\left(\right.$ e.g. $\left.1 \times 10^{-4}\right)$ for similar design parameter values and their corresponding degree of uncertainty, it is observed that the slope inclination of the cover soil needs to be lowered significantly, which is undesirable for the landfill operator. There needs to be a

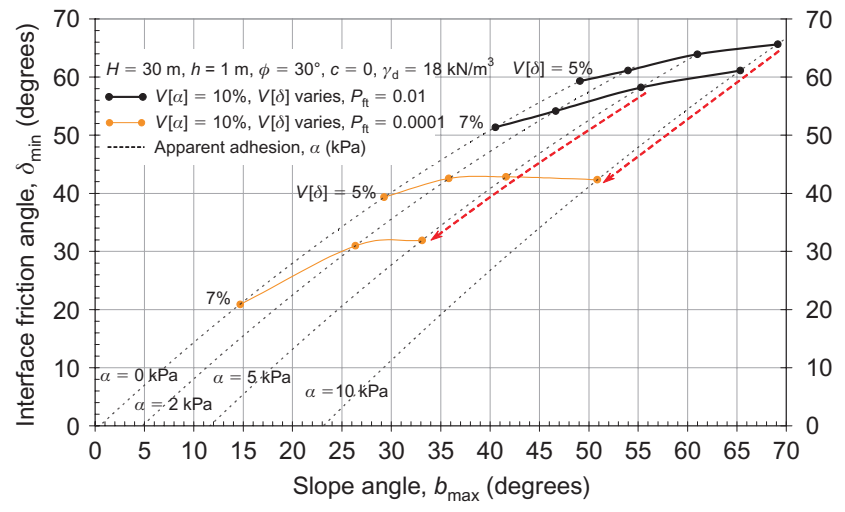

Figure 16. Comparison between $P_{\mathrm{ft}}$ of $1 \times 10^{-2}$ and $1 \times 10^{-4}$ on reliability-based design chart 
consensus between operator, designer and legislator on the degree of acceptable failure or unacceptable performance before reliability-based design can be practised to optimise design.

\section{CONCLUSIONS}

A design chart is a useful graphical tool for assessing the behaviour of a stability model for preliminary design, and to obtain both a safe and an optimum design. Two types of design chart have been produced, based on the modified limit equilibrium two-wedge method for evaluating the stability of veneer cover soil. The deterministic design chart provides information regarding the minimum interface shear strength or maximum slope angle to achieve FS of 1.5 ; the reliability-based design chart is capable of providing similar information, and also the allowable uncertainties associated with the design parameters. However, the latter chart imposes a more stringent criterion in the selection of lining materials, and requires practitioners to conduct more interface shear tests. This produces higher confidence in the selection of lining materials for design. The reliability-based design chart presented in the paper is not currently able to consider different cover soil characteristics, types of loading or their corresponding uncertainties. Nevertheless, it is a step forward towards reliability-based design, and demonstrates the importance of understanding uncertainty in design. The current practice using target factors of safety is not able to reflect this uncertainty, and therefore its use will at times result in unsafe designs. The reliability approach could be standardised, and may become a requirement in the future for landfill engineering design. A key consideration is the relationship between the financial risk that results from an unsafe design and the additional costs incurred in obtaining input data for, and carrying out, a reliability-based design.

\section{APPENDIX. DERIVATIVES OF FS WITH INPUT PARAMETERS}

Interface adhesion:

$$
\frac{\partial \mathrm{FS}}{\partial \alpha}=\frac{1}{\gamma_{\mathrm{d}} h \sin b}
$$

Interface friction:

$$
\frac{\partial \mathrm{FS}}{\partial \delta}=\frac{\cos b\left(1+\tan ^{2} \delta\right)}{\sin b}
$$

Unit weight of cover soil:

$$
\begin{aligned}
\frac{\partial \mathrm{FS}}{\partial \gamma_{\mathrm{d}}}= & \frac{\cos b \tan \delta}{\gamma_{\mathrm{d}} \sin b}-\frac{\alpha+\gamma_{\mathrm{d}} h \cos b \tan \delta}{\gamma_{\mathrm{d}}^{2} h \sin b} \\
& +\frac{h \tan \phi / 2 \gamma_{\mathrm{d}} H \cos b \sin b}{\cos b-\sin b \tan \phi} \\
& -\frac{c+\left(\gamma_{\mathrm{d}} h \tan \phi / 2 \cos b\right)}{\gamma_{\mathrm{d}}^{2} H \sin b(\cos b-\sin b \tan \phi)}
\end{aligned}
$$

Cover soil thickness:

$$
\begin{aligned}
\frac{\partial \mathrm{FS}}{\partial h}= & \frac{\cos b \tan \delta}{h \sin b}-\frac{\alpha+\gamma_{\mathrm{d}} h \cos b \tan \delta}{\gamma_{\mathrm{d}} h^{2} \sin b} \\
+ & \frac{\tan \phi}{2 H \cos b \sin b(\cos b-\sin b \tan \phi)}
\end{aligned}
$$

Cover soil cohesion:

$$
\frac{\partial \mathrm{FS}}{\partial c}=\frac{1}{\gamma_{\mathrm{d}} H \sin b(\cos b-\sin b \tan \phi)}
$$

Cover soil friction:

$$
\begin{aligned}
\frac{\partial \mathrm{FS}}{\partial \varphi}= & \frac{1+\tan ^{2} \phi}{2 h H \cos b \sin b(\cos b-\sin b \tan \phi)} \\
& +\frac{c+\left(\gamma_{\mathrm{d}} h \tan \phi / 2 \cos b\right)}{\gamma_{\mathrm{d}} H(\cos b-\sin b \tan \phi)^{2}}-\left(1+\tan ^{2} \phi\right)
\end{aligned}
$$

Landfill height:

$$
\frac{\partial \mathrm{FS}}{\partial H}=\frac{-\left[c+\left(\gamma_{\mathrm{d}} h \tan \phi / 2 \cos b\right)\right]}{\gamma_{d} H^{2} \sin b(\cos b-\sin b \tan \phi)}
$$

Veneer slope inclination:

$$
\begin{aligned}
\frac{\partial \mathrm{FS}}{\partial b}= & -\tan \delta-\frac{\alpha+\gamma_{\mathrm{d}} h \cos b \tan \delta}{\gamma_{\mathrm{d}} h \sin ^{2} b} \cos b \\
& +\frac{h \tan \phi}{2 H \cos ^{2} b(\cos b-\sin b \tan \phi)} \\
& -\frac{\left[c+\left(\gamma_{\mathrm{d}} h \tan \phi / 2 \cos b\right)\right] \cos b}{\gamma_{\mathrm{d}} H \sin ^{2} b(\cos b-\sin b \tan \phi)} \\
& -\frac{\left[c+\left(\gamma_{\mathrm{d}} h \tan \phi / 2 \cos b\right)\right](-\sin b-\cos b \tan \phi)}{\gamma_{\mathrm{d}} H \sin b(\cos b-\sin b \tan \phi)^{2}}
\end{aligned}
$$

\section{NOTATIONS}

Basic SI units are given in parentheses:

$c$ cohesion of the cover soil $(\mathrm{Pa})$

$h$ thickness of cover soil (m)

$C_{\mathrm{A}}$ resistance due to interface adhesion along active wedge $(\mathrm{N} / \mathrm{m})$

$C_{\mathrm{P}}$ resistance due to cohesion of cover soil along passive wedge $(\mathrm{N} / \mathrm{m})$

$E_{\mathrm{A}}, E_{\mathrm{P}}$ resultant forces acting between active and passive wedge $(\mathrm{N} / \mathrm{m})$

$F_{\mathrm{A}}, F_{\mathrm{P}}$ resultant force acting at base of the active or passive wedge $(\mathrm{N} / \mathrm{m})$

FS factor of safety against sliding (dimensionless)

$H$ Height of landfill (m)

$N_{\mathrm{A}}, N_{\mathrm{P}}$ normal resultant force acting at base of active or passive wedge $(\mathrm{N} / \mathrm{m})$ 
$T_{\mathrm{gs}} \quad$ tension force from anchored geosynthetics $(\mathrm{N} / \mathrm{m})$

$V[\cdot] \quad$ coefficient of variation; defined as ratio of standard deviation over mean; mean value of parameter stated in the brackets (dimensionless)

$W_{\mathrm{A}}, W_{\mathrm{P}}$ weight of active or passive wedge $(\mathrm{N} / \mathrm{m})$

$\alpha$ apparent adhesion of interface $(\mathrm{Pa})$

$\beta$ reliability index (dimensionless)

$\gamma_{\mathrm{d}}$ dry unit weight of cover soil $\left(\mathrm{N} / \mathrm{m}^{3}\right)$

$\delta$ interface friction angle (degrees)

$\mu_{\mathrm{FS}}$ mean value of FS (dimensionless)

$\sigma_{\mathrm{FS}} \quad$ standard deviation of FS (dimensionless)

$\tau_{\mathrm{IN}}$ interface shear strength; defined in Equation $12(\mathrm{~Pa})$

$\tau_{\text {soil }}$ shear strength of cover soil; defined in Equation $13(\mathrm{~Pa})$

$\phi$ friction angle of cover soil (degrees)

$\Phi(\cdot) \quad$ standard normal distribution function (dimensionless)

\section{REFERENCES}

Baecher, G. B. (1987). Geotechnical risk analysis user's guide. FHWA/ RD-87-011, Federal Highway Administration, McLean, 55 pp.

Cole, K. W. (1980). Factors of safety and limit state design in geotechnical engineering. Lecture given to the Scottish Geotechnical Group, Glasgow (referenced in Smith 1981).

D'Hollander, R. D. (2002). Reflections on appropriate reliability values for geosynthetic design. Proceedings of the GRI-16 Conference on Hot Topics in Geosynthetics - III, Folsom, PA, pp. 75-80.

Dixon, N., Jones, D. R. V. \& Fowmes, G. J. (2006). Interface shear strength and its use in reliability-based landfill stability analysis. Geosynthetics International, 13, No. 1, 1-14.
Duncan, J. M. (2000). Factors of safety and reliability in geotechnical engineering. Journal of Geotechnical and Geoenvironmental Engineering, 126, No. 4, 307-316.

Gilbert, R. B. (2001). Peak versus residual strength for waste containment systems. Proceedings of the GRI-15 Conference on Hot Topics in Geosynthetics - II, Folsom, PA, pp. 29-39.

Giroud, J. P., Williams, N. D., Pelte, T. \& Beech, J. F. (1995). Stability of geosynthetic-soil layered systems on slopes. Geosynthetics International, 2, No. 6, 1115-1148.

Koerner, R. M. (2002). Beyond factor of safety: the probability of failure. Proceedings of the GRI-16 Conference on Hot Topics in Geosynthetics - III, Folsom, PA, pp. 1-18.

Koerner, R. M. \& Hwu, B.-L. (1991). Stability and tension considerations regarding cover soils on geomembrane lined slopes. Geotextiles and Geomembranes, 10, No. 4, 335-355.

Koerner, R. M. \& Soong, T.-Y. (2005). Analysis and design of veneer cover soils. Geosynthetics International, 12, No. 1, 28-49.

Sabatini, P. J., Griffin, L. M., Bonaparte, R., Espinoza, R. D. \& Giroud, J. P. (2002). Reliability of state of practice for selection of shear strength parameters for waste containment system stability analyses. Geotextiles and Geomembranes, 20, No. 4, 241-262.

Sia, A. H. I. (2007). Landfill Lining Engineering Designs: A Probabilistic Approach. PhD thesis, Civil and Building Engineering, Loughborough University, UK.

Sia, A. H. I. \& Dixon, N. (2006). Development of graphical design charts for the stability of veneer cover soil. Proceedings of the 8th International Conference on Geosynthetics, Millpress, Rotterdam, pp. 281-286.

Sia, A. H. I. \& Dixon, N. (2007). Distribution and variability of interface shear strength and derived parameters. Geotextiles and Geomembranes, 25, No. 3, 139-154.

Smith, D. N. (1981). Probability theory in geotechnics: an introduction. Ground Engineering, 14, No. 7, 29-34.

USACE (1999). Risk-based analysis in geotechnical engineering for support of planning studies. Engineering Technical Letter No. 1110-2-556 [online], Washington, DC. Available at: http://www.usace.army.mil/inet/usace-docs/eng-tech-ltrs/etl1110-2556/a-b.pdf [Accessed 20 February 2004].

The Editor welcomes discussion on all papers published in Geosynthetics International. Please email your contribution to discussion@geosynthetics-international.com by 15 August 2008. 